\title{
Analysis on Genetic Diversity of Radix Astragali by ISSR Markers
}

\author{
Yaling Liu',2, Pengfei Zhang1, Ru Zhang1, Meiling Song1, Fengbo Liu², Wenquan Wang2,3*, Junling Hou ${ }^{3 *}$ \\ ${ }^{1}$ College of Life Science, Shanxi Agricultural University, Taigu, China \\ ${ }^{2}$ School of Chinese Pharmacy, Beijing University of Chinese Medicine, Beijing, China \\ ${ }^{3}$ Institute of Medicinal Plant Development, Chinese Academy of Medical Sciences \& Peking Union Medical College, Beijing, China \\ Email:*wwq57@126.com,*mshjl@126.com.
}

How to cite this paper: Liu, Y.L., Zhang, P.F., Zhang, R., Song, M.L., Liu, F.B., Wang, W.Q. and Hou, J.L. (2016) Analysis on Genetic Diversity of Radix Astragali by ISSR Markers. Advances in Bioscience and Biotechnology, 7, 381-391. http://dx.doi.org/10.4236/abb.2016.710037

Received: May 3, 2016

Accepted: October 16, 2016

Published: October 20, 2016

Copyright () 2016 by authors and Scientific Research Publishing Inc. This work is licensed under the Creative Commons Attribution International License (CC BY 4.0).

http://creativecommons.org/licenses/by/4.0/

\begin{abstract}
Radix Astragali has been an important traditional Chinese herbal medicine for over 2000 years. It is derived from two plant species, namely, Astragalus mongholicus [Astragalus membranaceus (Fisch.) Bge. var. mongholicus (Bge.) Hsiao] and Astragalus membranaceus [Astragalus membranaceus (Fisch.) Bge.] (Leguminosae), according to the Pharmacopoeia of the People's Republic of China. In this study, the genetic diversity and genetic relationships of Radix Astragali in China were analyzed by Inter-Simple Sequence Repeat (ISSR) markers. A total of 25 highly polymorphic ISSR primers were selected to amplify 95 Radix Astragali samples. Among 273 DNA bands amplified, 213 are polymorphic (percentage of polymorphic bands: $78 \%$ ). The average value of the amplified bands was 10.9 for each primer, and the number varied from 4 to 20. The genetic diversity of the 95 Radix Astragali samples was analyzed by using POPGENE 1.32 software. The Nei's genetic diversity index $(h)$ and Shannon's information index $(I)$ were 0.3590 and 0.5308 , respectively, which indicated the abundant genetic diversity of Radix Astragali. The level of genetic diversity in $A$. membranaceus ( $h: 0.3109, I: 0.4657$ ) was slightly lower than that in $A$. mongholicus ( $h$ : $0.3364, I: 0.4969$ ). Considering the average genetic similarity coefficient by NTSYS analysis to cluster the A. membranaceus of nine habitats and $A$. mongholicus of five habitats, Radix Astragali samples were clustered into two groups according to place of origin. This clustering is different from traditional clustering, which divides groups according to species. Results obtained from this study will provide a theoretical basis for the molecular study on germplasm resources of Radix Astragali.
\end{abstract}

\section{Keywords}

Radix Astragali, ISSR, Genetic Diversity 


\section{Introduction}

Radix Astragali, which has a long history of medicinal use, is derived from Astragalus mongholicus and Astragalus membranaceus [1]. Astragalus is mainly distributed in North, Northeast, Northwest, and Southwest China [2]. However, the qualitative difference between wild and cultivated Astragalus owing to the determination of genuine raw materials results in significant difference in market price, which leads to excavation of wild herbs. Thus, the distribution and population of wild Astragalus have rapidly decreased. Astragalus has been included in the national list of protected rare and endangered plants [3]. Effective conservation of germplasm resources of Radix Astragali is urgently needed. Although the artificial cultivation of Astragalus has achieved success, the qualitative and quantitative demands of raw material for medicine have greatly increased with the development of new drugs, medicine, and health products. Astragalus cultivation has produced hybrid varieties with unstable yield and low quality. This phenomenon has seriously affected the further development of Astragalus industry. Therefore, this preliminary study on Astragalus from different habitats was conducted to evaluate its genetic diversity by using the ISSR labeling technique. The findings will provide a theoretical basis for formulating Astragalus genetic diversity research, conservation strategies, and cross breeding.

ISSR was conducted by using a synthetic 16 - 18 bp nucleotide repeat sequence as a primer. Genomic DNA was amplified by PCR, which employed a primer anchored at 3 or 5 end of oligonucleotides. The ISSR combines the advantages of RAPD and SSR markers at the same level. Thus, it can produce more polymorphism than RAPD, and the reaction system is more sensitive, more stable, and has good repeatability [4]-[7]. This molecular marker has been widely used in studies on germplasm resource identification, phylogeny of species, plant taxonomy, evolution, and genetic diversity [8]-[10]. Astragalus has several variations of morphological features in the actual production, such as stems with red or green color and stems with two colors. Variation and degradation of the Astragalus germplasm may occur in the introduction and domestication. Thus, studying the genetic diversity of Radix Astragali at the DNA level is necessary. This study provides molecular-level evidence for Astragalus germplasm resources by using the ISSR molecular marker.

\section{Materials and Methods}

\subsection{Plant Materials and DNA Extraction}

A total of 95 Radix Astragali individuals were sampled representing 10 natural populations, including Shanxi, Jilin, Inner Mongolia, Gansu, Ningxia, and Shaanxi Provinces of China (Table 1). Approximately $1 \mathrm{~g}$ of fresh leaf samples from each individual was collected, placed in a plastic bag with silica gel to dry the samples quickly, and brought back to the laboratory for DNA isolation. Total genomic DNA was extracted using a protocol described by Doyle and Doyle [11], and 0.6\% agarose gel electrophoresis and a biospec-mini DNA/RNA/protein analyzer were used to detect the quality and yield of DNA. The DNA was later diluted to $50 \mathrm{ng} \cdot \mu \mathrm{L}^{-1}$ working solution and placed in a refri 
Table 1. Resources of the test samples.

\begin{tabular}{ccc}
\hline Source & Species & Sample number \\
\hline China Shanxi Hunyuan & A. mongholicus & 33 \\
China Inner Mongolia Hulunbeier & A. mongholicus, A. membranaceus & 20 \\
China Ningxia Guyuan & A. membranaceus & 3 \\
China Shandong Linyi & A. membranaceus & 7 \\
China Shaanxi Baoji & A. mongholicus, A. membranaceus & 3 \\
China Gansu Dingxi & A. mongholicus, A. membranaceus & 7 \\
China Hebei Anguo & A. mongholicus, A. membranaceus & 8 \\
China Heilongjiang Hailin & A. membranaceus & 7 \\
China Liaoning Beixi & A. membranaceus & 5 \\
China Jilin Tonghua & A. membranaceus & 3 \\
\hline
\end{tabular}

gerator at $4^{\circ} \mathrm{C}$ for future use.

\subsection{Primer Selection and ISSR-PCR Amplification}

To determine the appropriate primers suitable for Astragali, we screened 100 ISSR primers purchased from the website of the University of British Columbia in Canada (https://www.ubc.ca/) and Synthesis Project. For each primer pair, two samples were amplified, and their amplification products were run on $1 \%$ agarose gels. PCR amplifications were performed in a $20 \mu \mathrm{L}$ reaction that contained $2 \mu \mathrm{L}$ of $10 \times$ PCR buffer, 2.5 mM dNTPs, $10 \mu \mathrm{M}$ primer, 5 unit of Taq DNA polymerase (Taka Ra Biotechnology Co., Ltd.), and $50 \mathrm{ng}$ of template DNA. Double distilled water was added to make the volume $20 \mu \mathrm{L}$. Amplifications were performed as follows: $95^{\circ} \mathrm{C}$ for $5 \mathrm{~min}, 35$ cycles of denaturation at $95^{\circ} \mathrm{C}$ for $30 \mathrm{~s}$, annealing at $53^{\circ} \mathrm{C}-57^{\circ} \mathrm{C}$ for $40 \mathrm{~s}$, extension at $72^{\circ} \mathrm{C}$ for $40 \mathrm{~s}$, and a final extension at $72^{\circ} \mathrm{C}$ for $10 \mathrm{~min}$. Afterward, the samples were held at $4^{\circ} \mathrm{C}$. Highly polymorphic primers with clear bands and clean background were selected to amplify the genomic DNA of all Astragalus species.

\subsection{Data Analysis}

The amplified DNA polymorphic fragments (bands) were scored as present (1) or absent (0), and the data matrix of the ISSR phenotypes was assembled for further analysis. The percentage of polymorphic bands $(P P B)$, observed number of alleles $(\mathrm{Na})$, effective number of alleles $(\mathrm{Ne})$, Nei's genetic diversity index $(h)$, and Shannon's information index $(I)$ were calculated using POPGENE 1.32 software. NTSYSpc 2.10 software was used to calculate the genetic similarity (Gs) coefficient of the 183 Astragalus species. The UPGMA tree [12] was constructed using NTSYS 1.8 software [13] to examine the relationship of the populations.

\section{Results}

\subsection{DNA Detection}

The genomic DNA of the 95 A. mongholicus and A. membranaceus were extracted and detected by agarose gel electrophoresis. The results showed that the DNA bands were 
clear, and no diffusion phenomena were observed. The extracted genomic DNA detected by a nucleic acid protein detector revealed that the ratio of D260 nm/D280 nm was between 1.8 and 2.0, and the yield was between 100 and $1800 \mathrm{ng} / \mu \mathrm{L}$. These findings indicate that the genomic DNA extracted from the Astragali leaves had high quality and high yield.

\subsection{ISSR Polymorphism}

A total of 35 primers were screened from 100 ISSR primers, which were published by the Columbia University, to study the genetic diversity of the two populations of Radix Astragali. Among these primers, 25 were polymorphic and 10 were monomorphic. The $P P B$ was $71.4 \%$. A total of 273 amplified bands were obtained from the 95 Radix Astragali samples using 25 polymorphic ISSR primers (Table 2). Among these bands, 213 were polymorphic, and the $P P B$ was $78 \%$. The average value of the amplified bands was 10.9 for each primer, and the number varied from 4 to 20 (Table 3). UBC835 and UBS855 presented the highest number of bands (20/19), whereas UBC811 and UBC808 had the lowest number (4/5). The results showed a significant genetic difference.

Table 2. Primer name and sequences used in the ISSR analysis.

\begin{tabular}{|c|c|c|}
\hline Primer & Primer sequence $\left(5^{\prime} \rightarrow 3^{\prime}\right)$ & $\operatorname{Tm}\left({ }^{\circ} \mathrm{C}\right)$ \\
\hline UBC807 & $(\mathrm{AG})_{8} \mathrm{~T}$ & 52 \\
\hline UBC808 & $(\mathrm{AG})_{8} \mathrm{C}$ & 55 \\
\hline UBC810 & $(\mathrm{GA})_{8} \mathrm{~T}$ & 52 \\
\hline UBC811 & $(\mathrm{GA})_{8} \mathrm{C}$ & 55 \\
\hline UBC812 & $(\mathrm{GA})_{8} \mathrm{~A}$ & 52 \\
\hline UBC817 & $(\mathrm{CA})_{8} \mathrm{~A}$ & 52 \\
\hline UBC818 & $(\mathrm{CA})_{8} \mathrm{G}$ & 55 \\
\hline UBC822 & $(\mathrm{TC})_{8} \mathrm{~A}$ & 52 \\
\hline UBC825 & $(\mathrm{AC})_{8} \mathrm{~T}$ & 52 \\
\hline UBC826 & $(\mathrm{AC})_{8} \mathrm{C}$ & 55 \\
\hline UBC827 & $(\mathrm{AC})_{8} \mathrm{G}$ & 55 \\
\hline UBC830 & $(\mathrm{TG})_{8} \mathrm{G}$ & 55 \\
\hline UBC834 & $(\mathrm{AG})_{8} \mathrm{YT}$ & 54 \\
\hline UBC835 & $(\mathrm{AG})_{8} \mathrm{YC}$ & 56 \\
\hline UBC836 & $(\mathrm{AG})_{8} \mathrm{YA}$ & 54 \\
\hline UBC 840 & $(\mathrm{GA})_{8} \mathrm{YT}$ & 54 \\
\hline UBC842 & $(\mathrm{GA})_{8} \mathrm{YG}$ & 56 \\
\hline UBC849 & $(\mathrm{GT})_{8} \mathrm{YA}$ & 54 \\
\hline UBC851 & $(\mathrm{GT})_{8} \mathrm{YG}$ & 56 \\
\hline UBC855 & $(\mathrm{AC})_{8} \mathrm{YT}$ & 54 \\
\hline UBC856 & $(\mathrm{AC})_{8} \mathrm{YA}$ & 54 \\
\hline UBC857 & $(\mathrm{AC})_{8} \mathrm{YG}$ & 56 \\
\hline UBC864 & ATGATGATGATGATGATG & 48 \\
\hline UBC899 & CATGGTGTTGGTCATTGTTCCA & 58 \\
\hline UBC900 & ACTTCCCCACAGGTTAACACA & 58 \\
\hline
\end{tabular}


Table 3. Statistical results of polymorphic bands of ISSR primers.

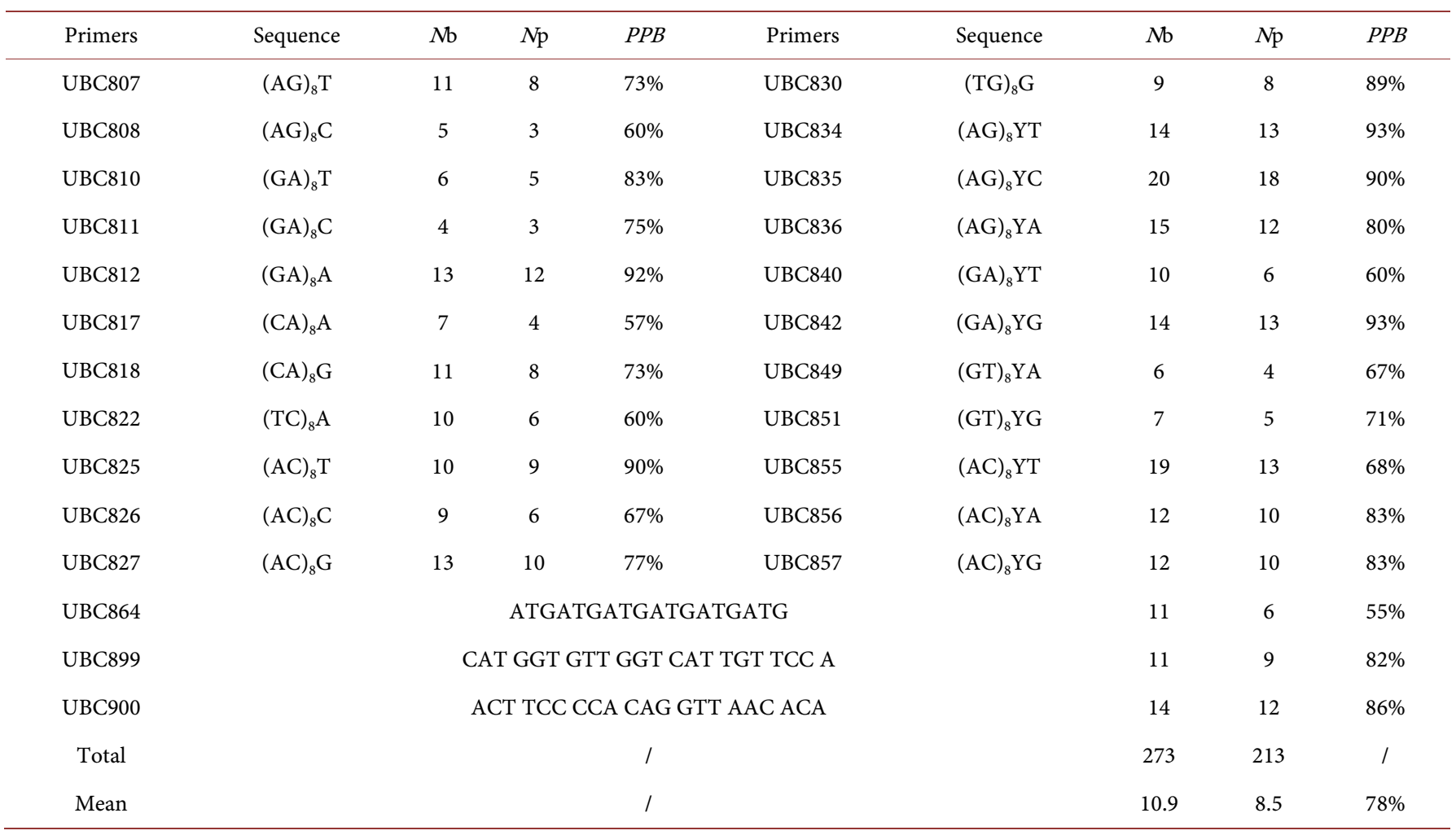

Note: $N \mathrm{~b}$ (Number of bands); $N \mathrm{p}$ (Number of polymorphic bands); $P P B$ (Percentage of polymorphic bands).

\subsection{Genetic Diversity of Radix Astragali}

The binary data matrix was scored as present (1) or absent (0) of homologous bands and loaded into POPGENE 1.32 software to analyze the genetic diversity of Radix $A s$ tragali. The mean Na was 1.9 in the two Astragalus species. For A. membranaceus, the $N e, h$, and $I$ were $1.5318,0.3109$, and 0.4657 , respectively, which were slightly lower than those of $A$. mongholicus (Ne: 1.5861, $h: 0.3364$, and $I: 0.4969$ ). These results indicate that $A$. mongholicus have higher genetic diversity than $A$. mongholicus (Table 4).

\subsection{Genetic Diversity of Two Radix Astragali from Different Regions}

A. membranaceus was collected from nine provinces including Inner Mongolia, Ningxia, Shandong, Shaanxi, Gansu, Hebei, Heilongjiang, Jilin, and Liaoning (Table 5). The highest number of polymorphic bands $(N \mathrm{p})$ of 190 was observed in Inner Mongolia. The $P P B, h$, and $I$ were $89.20 \%, 0.2538$, and 0.3714 , respectively. The lowest $N \mathrm{p}$ was found in Shaanxi with only 83 . The $P P B, h$, and $I$ were $38.97 \%, 0.0861$, and 0.1260 , respectively. These results indicate the different origins and order of $A$. membranaceus genetic diversity from highest to lowest: Inner Mongolia, Heilongjiang, Ningxia, Shandong, Heibei, Gansu, Jilin, Liaoning, and Shaanxi. Meanwhile, A. mongholicus was collected from five provinces including Shanxi, Inner Mongolia, Shaanxi, Gansu, and Hebei (Table 5). The highest $N \mathrm{p}$ of 203 was observed in Shanxi. The $P P B, h$, and $I$ were 95.3\%, 0.4877, and 0.5212, respectively. The lowest $N \mathrm{p}$ was observed in Shaanxi with 
Table 4. Genetic diversity of two species of radix astragali.

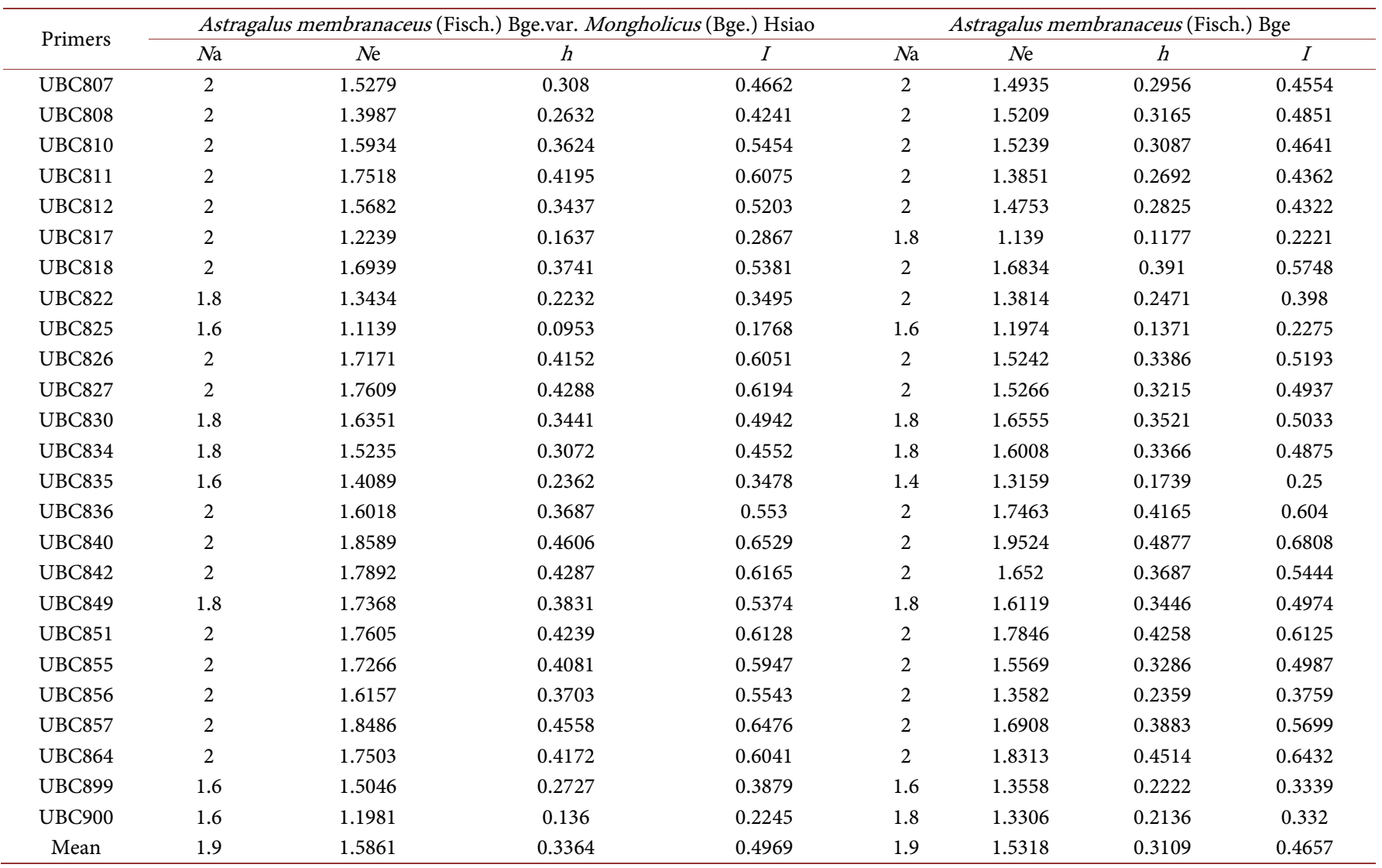

Note: $N \mathrm{a}$ (Number of Aelle), $N$ e (Number of effect Aelle); $h$ (Nei's gene diversity); $I$ (Shannon's information index).

Table 5. Genetic diversity of radix astragali of different origins.

\begin{tabular}{|c|c|c|c|c|c|c|}
\hline Origin & $\mathrm{Na}$ & $\mathrm{Ne}$ & $h$ & $I$ & $N \mathrm{p}$ & $P P B$ \\
\hline \multicolumn{7}{|c|}{ Astragalus membranaceus (Fisch.) Bge } \\
\hline Inner Mongolia & 1.6452 & 1.4497 & 0.2538 & 0.3714 & 190 & $89.20 \%$ \\
\hline Ningxia & 1.3306 & 1.2338 & 0.1370 & 0.1999 & 117 & $54.93 \%$ \\
\hline Shanxi & 1.2086 & 1.1472 & 0.0861 & 0.1260 & 83 & $38.97 \%$ \\
\hline Gansu & 1.3710 & 1.2194 & 0.1288 & 0.1942 & 121 & $56.81 \%$ \\
\hline Jilin & 1.3226 & 1.1913 & 0.1121 & 0.1686 & 111 & $52.11 \%$ \\
\hline Liaoning & 1.2339 & 1.1467 & 0.0868 & 0.1296 & 92 & $43.19 \%$ \\
\hline Mean & 1.4040 & 1.2621 & 0.1516 & 0.2245 & 129 & $60.51 \%$ \\
\hline \multicolumn{7}{|c|}{ A. membranaceus (Fisch.) Bge.var. Mongholicus (Bge.) Hsiao } \\
\hline Shanxi & 1.8500 & 1.6157 & 0.4877 & 0.5212 & 203 & $95.31 \%$ \\
\hline Hebei & 1.3952 & 1.2528 & 0.1461 & 0.2174 & 127 & $59.62 \%$ \\
\hline Mean & 1.5297 & 1.3546 & 0.2324 & 0.3044 & 145 & $68.17 \%$ \\
\hline
\end{tabular}

Note: $N \mathrm{a}$ (Number of Aelle); $N \mathrm{e}$ (Number of effect Aelle); $h$ (Nei's gene diversity); $N$ p (Number of polymorphic bands); $I$ (Shannon's information index); $P P B$ (Percentage of polymorphic bands). 
only 87 . The $P P B, h$, and $I$ were $40.85 \%, 0.0869$, and 0.126 , respectively. These results indicate the different origins and order of $A$. mongholicus genetic diversity from highest to lowest: Shanxi, Heilongjiang, Hebei, Gansu, and Shaanxi. At a general level, the average value ( $h: 0.1516, I: 0.2245, P P B: 60.51 \%$ ) of the genetic diversity of $A$. membranaceus from the nine provinces was slightly lower than the value ( $h: 0.2324,1: 0.3044$, PPB: 68.17\%) of A. mongholicus from the five provinces.

\subsection{Clustering Analysis of Radix Astragali}

The $G$ s coefficient of nine origins of $A$. membranaceus and five origins of $A$. mongholicus was calculated using NTSYSpc 2.10 software, and UPGMA was used to generate a dendrogram (Figure 1). The 14 different origins of two Astragali could be completely separated into two parts based on 0.80 coefficient using the 25 ISSR primers. One group cluster consisted of the northern regions including Inner Mongolia, Shanxi, Shandong, Heilongjiang, Hebei, Jilin, and Liaoning, and the other group cluster consisted of Ningxia, Gansu, and Shaanxi. This first group was clustered according to place of origin and conformed to the geographical characteristic of the traditional Chinese medicinal material geoherbalism. The large group was also divided into two groups according to production. One group includes Shanxi and Inner Mongolia. Cluster was initially observed with $A$. mongolian of Shanxi and Inner Mongolia at 0.93 and then with $A$. membranaceus of Inner Mongolia at 0.91. The other group includes five districts, namely, Shandong, Heilongiiang, Hebei, Jilin, and Liaoning, which were mostly from $A$. membranaceus. The major second group mainly includes three origins, namely, Ningxia, Gansu, and Shaanxi. The membrane pod of A. membranaceus and A. mongholicus of Gansu Province was clustered as a group at 0.88. After Shaanxi $A$. mongolian clustering, A. membranaceus of Ningxia formed the second group.

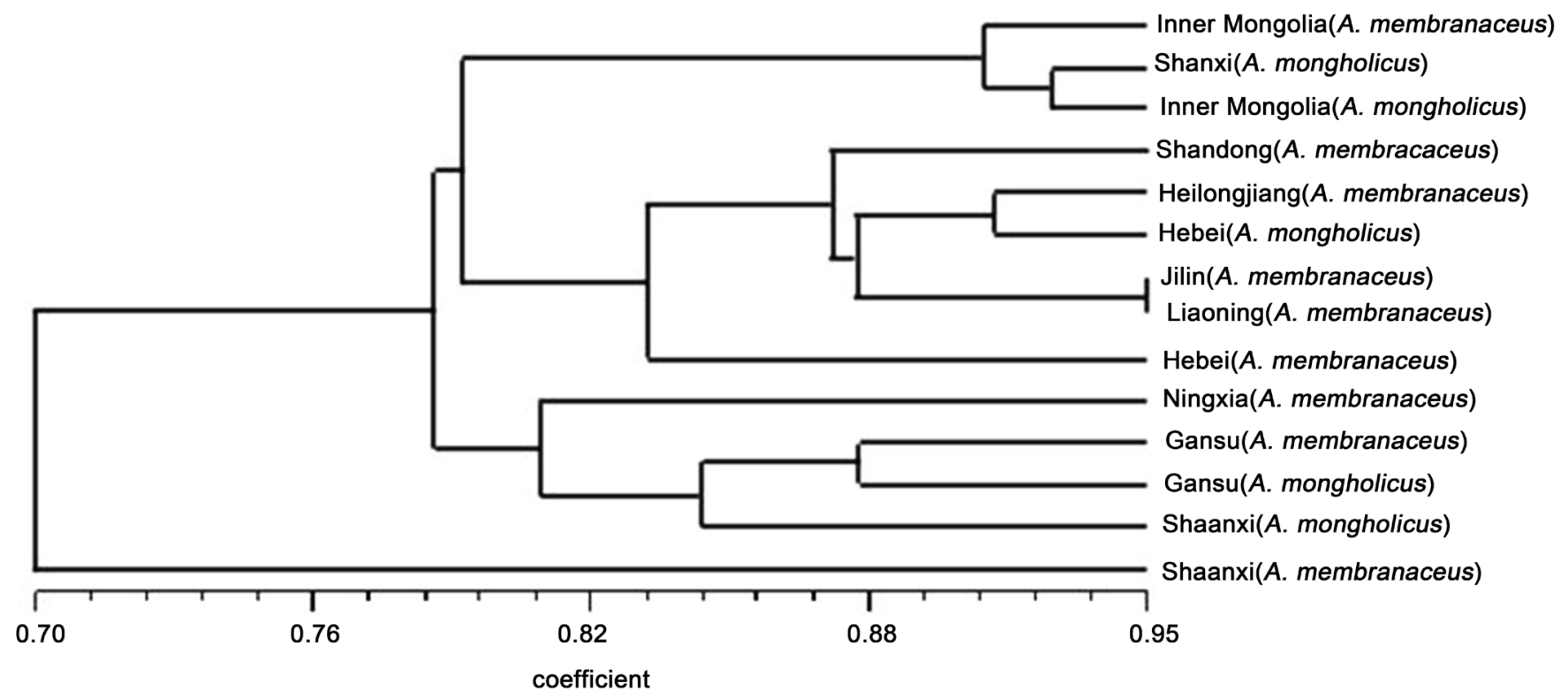

Figure 1. Dendrogram of $G$ s among the radix astragali from different habitats. 


\section{Discussion}

\subsection{Genetic Diversity}

Genetic diversity is the product of the long-term evolution of a species or a population. It is the basis of existence, development, and evolution of species. Therefore, the study on the genetic diversity of species is fundamental to understand the taxonomy, origin, and evolution of species. Furthermore, such study will provide a theoretical basis for the germplasm resource conservation, development, utilization, and breeding [14]. In the present study, the genetic diversity of 95 Astragalus materials was analyzed by using 25 highly repeatable and polymorphic ISSR primers. A. mongholicus had higher genetic diversity ( $h: 0.3364, I: 0.4969)$ than $A$. membranaceus ( $h: 0.3109, I: 0.4657$ ) at the species level (Table 4). The results of this study were consistent with the findings ( $A$. mongholicus, $h$ : 0.822; A. membranaceus, $h$ : 0.689 ) of the research on genetic diversity of the two species by SSR molecular marker [15]. Compared with a relevant research [16], we speculated that $A$. mongholicus had a higher level of genetic diversity.

Astragalus mainly depends on insect for pollination and on humans for seed dispersal; it also possesses distant hybridization properties [17]-[19]. These life history traits are dominated by outcrossing breeding system and considered as an important factor to maintain higher genetic diversity of species [20]-[22]. The wild Astragalus resource gradually decreased mainly because of the recent over-excavation and habitat deterioration caused by human activity [23] [24]. However, the interference is likely only the effect of the number and genetic diversity of parts of a local area of Astragalus, in addition to the fact that the species are perennial herbaceous plants with high medicinal value. Thus, the large range of distribution, long life cycle, and germplasm (seed) exchanges in the development and propagation can be conducive to the genetic diversity at the species level [21] [25]. Therefore, the genetic diversity of the two species of $A s$ tragalus is unaffected by severe loss of habitat and human destruction.

\subsection{Analysis and Diversity of Two Species of Astragalus in Different Habitats}

The genetic diversity of different habitats of the two species of medicinal Astragalus was analyzed. The genetic diversity index of $A$. membranaceus was the highest in Heilongjiang (Np: 183, PPB: 86.13\%, h: 0.2321, I: 0.3465) and the lowest in Shaanxi (Np: 83, PPB: 39.1\%, $h: 0.0861, I: 0.1260)$. Meanwhile, $A$. mongholicus polymorphic loci were the highest in Shanxi (Np: 203, PPB: 95.3\%, h: 0.4877, I: 0.5212) and the lowest in Shaanxi (Np: $87, P P B: 40.97 \%, h: 0.0869, I: 0.1268$ ). Thus, the genetic diversity level is basically consistent in $A$. membranaceus and A. mongholicus, which have higher genetic diversity in the genuine habitat. These phenomena may be attributed to the abundant germplasm resource and traditional history in development and utilization. At a general level, the genetic diversity of $A$. membranaceus from the nine provinces ( $h: 0.1516, I: 0.2245, P P B$ : $60.51 \%)$ was slightly lower than that of $A$. mongholicus from the five provinces ( $h$ : 0.2324, I: $0.3044, P P B: 68.17 \%)$. This result may be due to the fact that $A$. mongholicus has high utilization rate (faster regeneration) and germplasm diversity [15] [26] [27]. 


\subsection{Analysis on the Genetic Relationships between Two Species of Astragalus in Different Habitats}

Results showed that the two medicinal Astragalus species from 10 different habitats could be clustered into two groups (Figure 1). In these groups, major clustering was based on the geographical habitats (Shanxi and Inner Mongolia) of $A$. membranaceus and A. mongholicus. The morphological characteristics and classification status of the two species showed a very close genetic relationship [2]. In addition, Shanxi and Inner Mongolia are areas where authentic Astragalus herbal medicine is real estate areas. Thus, the first clustering was according to place of origin. However, Hebei A. mongholicus merged into different geographical positions in the clustering, which may be due to its mixed medicinal material source. Hebei is the largest business center; thus, seed and germplasm mix into the genetic information of the two species. Another group of three habitats of $A$. membranaceus and A. mongholicus, including Ningxia, Gansu, and Shaanxi, was clustered into one category from Gansu. The recorded change for the famous region of Astragalus in history is from Sichuan to Gansu, Shaanxi, Ningxia, Shanxi, Inner Mongolia, and gradual migration to Northeast Heilongjiang. Main cultivated varieties of $A$. membranaceus also replaced $A$. Mongholicus. Based on the classification of $A$. mon-gholicus from $A$. membranaceus variants, the genetic relationship is very close. The experimental results also presented that these species were divided according to origin and not from species distinction. This clustering also showed that the genetic relationship was close and may be related to the dominant characteristics of ISSR molecular markers.

\subsection{Protection Strategy of Astragalus Germplasm Resources}

In summary, two Astragalus species currently maintained a middle genetic diversity level. Genetic diversity is the basis of species to adapt to the environment and evolution to avoid extinction and survive. Genetic diversity also provides theoretical basis for further development and utilization of germplasm resources. The current anthropogenic deforesting and picking activities as well as habitat deterioration do not seriously affect the Astragalus genetic diversity. However, if the deterioration of the environment and damage induced by human activities are ineffectively prevented, the fragmentation of Astragalus habitat and population scale is bound to accelerate. This phenomenon can cause a genetic drift in its population and lead to a substantial loss of the current abundant genetic diversity. Such loss will affect the survival of the species and the availability of excellent germplasm resources. The main reasons of wild Astragalus resource loss are deliberate cutting and picking, as well as habitat destruction. We suggest that Astragalus protection area should be established as soon as possible in wild Astragalus habitat to prohibit unauthorized and wasteful mining. Detailed plan about development and utilization should also be designed. Considering that the current biological research on Astragalus is few, we suggest further research on the reproductive biology, conservation genetics, and physiological and ecological aspects to provide basis for the conservation and sustainable utilization of these species. 


\section{Acknowledgements}

This study was supported by the National Natural Science Foundation of China (31400285), the Chinese herbal medicine standardization production technology service platform [ministry of consumption (2011) 340], Breed Foundation of Shanxi Agricultural University (No. 2014YZ10).

\section{References}

[1] China Pharmacopoeia Committee (2015) Pharmacopoeia of People's Republic of China, Vol. 1. Chemical Industry Press, Beijing, 302-303.

[2] Zhao, Y.Z. (2006) Taxonomy and Floristic Geographical Distribution of the Chinese Medicinal Huangqi. Bulletin of Botanica Research, 26, 532-538.

[3] Fu, L.G. (1992) In China Plant Red Data Book-Rare and Endangered Plants, Vol. 1. Science Press, Beijing, 372-373.

[4] Gllbert, J.E., Lewis, R.V., Wilkinson, M.J. and Caligari, P.D.S. (1999) Developing an Appropriate Strategy to Assess Genetic Variability in Plant Germplasm Collections. Theoretical and Applied Genetics, 98, 1125-1131. http://dx.doi.org/10.1007/s001220051176

[5] Prevost, A. and Wilkinson, M.J. (1999) A New System of Comparing PCR Primers Applied to ISSR Fingerprinting of Potato Cultivars. Theoretical and Applied Genetics, 98, 107-112. http://dx.doi.org/10.1007/s001220051046

[6] Farsani, T.M., Etemadi, N., Sayed-Tabatabaei, B.E. and Talebi, M. (2012) Assessment of Genetic Diversity of Bermudagrass (Cynodon_dactylon) Using ISSR Markers. International Journal of Molecular Sciences, 13, 383-392. http://dx.doi.org/10.3390/ijms13010383

[7] Omondi, E.O., Debener, T., Linde, M., Abukutsa-Onyango, M., Dinssa, F.F. and Winkelmann, T. (2016) Molecular Markers for Genetic Diversity Studies in African Leafy Vegetables. Advances in Bioscience and Biotechnology, 7, 188-197. http://dx.doi.org/10.4236/abb.2016.73017

[8] Ansari, S.A., Narayanan, C., Wali, S.A., Kumar, R., Shukal, N. and Rahangdale, S.K. (2012) ISSR Markers for Analysis of Molecular Diversity and Genetic Structure of Indian Teak (Tectona grandis L.f.) Populations. Annals of Forest Research, 55, 11-23.

[9] Narzary, D., Rana, T.S. and Ranade, S.A. (2012) Genetic Diversity in Inter-Simple Sequence Repeat Profiles across Natural Populations of Indian Pomegranate (Punica granatum L.). Plant Biology, 12, 806-813. http://dx.doi.org/10.1111/j.1438-8677.2009.00273.x

[10] Farsani, T.M., Etemadi, N., Sayed-Tabatabaei, B.E. and Talebi, M. (2012) Assessment of Genetic Diversity of Bermudagrass (Cynodon dactylon) Using ISSR Markers. International Journal of Molecular Sciences, 13, 383-392. http://dx.doi.org/10.3390/ijms13010383

[11] Doyle, J.J. and Doyle, J.L. (1987) A Rapid DNA Isolation Procedure for Small Quantities of Fresh Leaf Tissue. Phytochemical Bulletin, 19, 11-15.

[12] Nei, M. (1978) Estimation of Average Heterozygosity and Genetic Distance from a Small Number of Individuals. Genetics, 89, 583-590.

[13] Rohlf, F.J. (1994) NTSYS-pc, Numerical Taxonomy and Multivariate Analysis System. Ver. 1. 80. Exeter Software, New York.

[14] Helenurm, K. (2001) High Levels of Genetic Polymorphism in the Insular Endemic Herb Jepsonia malvifolia. Journal Heredity, 92, 427-432. http://dx.doi.org/10.1093/jhered/92.5.427

[15] Wang, A. (2013) Genetic Diversity Analysis of Astragalus mongholicus and A. mem- branaceus. Minzu University of China, Beijing. 
[16] Jin, Z.F., Piao, X.C., Wu, S.Q. and Wu, R.Z. (2007) Analysis of Genetic Diversity in Astragalus membranaceus Germplasms by RAPD Markers. Hubei Agricultural Sciences, 46, 875-876

[17] Feng, X.J. (2011) Study on Pollination Characteristic of Mongolia Milkvetch. Modern Chinese Medicine, 13, 24-26.

[18] Zhang, J., Yang, F.J. and Liu, S. (2010) Study on Pollinating in Sects of Astragalus membranaceus (Ficsh) Bunge. Journal of Anhui Agricultural Sciences, 38, 2883-2885.

[19] Wu, S.Q. and Lian, M.L. (2008) Study on Pollinating on Characteristic of Radix astragali. Journal of Anhui Agricultural Sciences, 36, 9184-9303.

[20] Zhang, J., Yang, F.J., Liu, S., Guo, S. and Ren, Y.Y. (2009) Breeding System Study in Astragalus membranaceus (Ficsh) Bunge. Ginseng Research, 3, 17-20.

[21] Nybom, H. and Bartish, I.V. (2000) Effects of Life History Traits and Sampling Strategies on Genetic Diversity Estimates Obtained with RAPD Markers in Plants. Perspectives in Plant Ecology, Evolution and Systematics, 3, 93-114. http://dx.doi.org/10.1078/1433-8319-00006

[22] Nybom, H. (2004) Comparison of Different Nuclear DNA Markers for Estimating Intraspecific Genetic Diversity in Plants. Molecular Ecology, 13, 1143-1155. http://dx.doi.org/10.1111/j.1365-294X.2004.02141.x

[23] Zhao, M., Duan, J.A., Huang, W.Z. and Zhou, R.H. (2000) The Analysis of Astragalus Linn. Medicinal Plants Resources Present Situation in Chinese. Chinese Wild Plant Resources, 19, 5-9.

[24] Zhang, L.T., Guo, B.L., Zhu, X.C. and Feng, G.Z. (2006) Survey of Astragalus germplasm Resources. Traditional Chinese Medicinal Materials, 29, 771-773.

[25] Hamrick, J.L. and Godt, M.J.W. (1996) Effects of Life History Traits on Genetic Diversity in Plant Species. Philosophical Transaction: Biological Sciences, 351, 1291-1298 http://www.jstor.org/stable/56204 http://dx.doi.org/10.1098/rstb.1996.0112

[26] Feng, X.J., Liu, G.K. and Liang, S.M. (2010) Review of Studies on Germplasm Resources of Mongolia Milkvetch. Journal of Shanxi Agricultural Sciences, 38, 95-98.

[27] Xie. X.L., Wang, X.S., Zhao, L., Wang, L. and Li, Y. (2004) Morphotype Diversity of Astragalus Membranaceus (Fisch.) Bge. Var. Mongholicus (Bge.) Hsiao. Journal of Anhui Agricultural Sciences, 32, 1203-1204.

Submit or recommend next manuscript to SCIRP and we will provide best service for you:

Accepting pre-submission inquiries through Email, Facebook, LinkedIn, Twitter, etc.

A wide selection of journals (inclusive of 9 subjects, more than 200 journals)

Providing 24-hour high-quality service

User-friendly online submission system

Fair and swift peer-review system

Efficient typesetting and proofreading procedure

Display of the result of downloads and visits, as well as the number of cited articles

Maximum dissemination of your research work

Submit your manuscript at: http://papersubmission.scirp.org/

Or contact abb@scirp.org 